\title{
Association of antecedent malnutrition with persistent diarrhoea: a case-control study
}

\author{
N Bhandari, M K Bhan, S Sazawal, J D Clemens, S Bhatnagar, V Khoshoo
}

\begin{abstract}
To determine the effect of nutritional state on persistent diarrhoea a case-control study was carried out on 756 children followed up prospectively for 18 months. Children who developed persistent diarrhoea were compared with population controls and controls with acute diarrhoea. The mean weight for age in the children with persistent diarrhoea $(69.9 \%)$ was significantly lower than that in the population controls $(\mathbf{7 7 . 0 \% )}$ and the diarrhoeal controls $(76 \cdot 2 \%)$. Weight for age of $\$ 70 \%$ was associated with persistent diarrhoea in both case-control analyses (population controls, matched odds ratio 3.25; diarrhoeal controls, matched odds ratio $2 \cdot 46$ ). The corrected odds (multiple logistic regression) in the two analyses were $3 \cdot 2(95 \%$ confidence interval 1.3 to $8 \cdot 1)$ and $3.4(1.2$ to $9 \cdot 1)$.

Weight for age of $\leqslant 70 \%$ increases the risk of persistent diarrhoea. In an underweight child there is a higher risk of diarrhoea becoming persistent. Prevention of malnutrition and intensive management of acute diarrhoea in malnourished children should help reduce the risk of the diarrhoea persisting.
\end{abstract}

\section{Introduction}

Diarrhoea and malnutrition are common in developing countries, especially among preschool children. Either of them places a child at a higher risk of dying. A mutually causative interaction between them has been proposed ${ }^{12}$ in which diarrhoea is believed to precipitate and exacerbate malnutrition ${ }^{3.5}$ while malnutrition predisposes to diarrhoea. ${ }^{6-8}$ Of these two interactions, the effect of diarrhoea on malnutrition is better documented. ${ }^{+}$

Reports on the effect of malnutrition on diarrhoeal morbidity are not consistent. Earlier studies reported an increase in the prevalence of acute diarrhoea among malnourished children, ${ }^{9-11}$ whereas two more recent studies found that malnourished children tend to have diarrhoea for longer but do not have a higher incidence of acute diarrhoea. ${ }^{12} 13$ These studies, however, did not evaluate other possible causes of prolonged diarrhoea and their potential influence on the observed association between antecedent malnutrition and duration of diarrhoea. Whether the risk factors for an increase in mean duration of acute diarrhoea-say, from four to seven days-are the same as those for persistent diarrhoea (duration $>14$ days) is also unclear.

We present the findings of a case-control study of children followed up longitudinally to evaluate the association of antecedent malnutrition and persistent diarrhoea.

\section{Subjects and methods}

\section{STUDY DESIGN AND STRATEGY}

We carried out two longitudinal case-control studies on children living in rural areas in north India. The first study comprised children who developed persist- ent diarrhoea (index children) and children matched for age who did not develop persistent diarrhoea during the study (population controls). In the second study the same children with persistent diarrhoea were separately compared with children matched for age who did not have persistent diarrhoea during the study but had acute diarrhoea within a month of the index child's illness (diarrhoeal controls). The prevalence of antecedent malnutrition in the first analysis allowed us to evaluate the association of malnutrition with persistent diarrhoea in the general population, whereas in the second analysis we evaluated the association of malnutrition with the persistence of diarrhoea after its onset.

A cohort was assembled at Anangpur, $30 \mathrm{~km}$ from Delhi, after an initial demographic survey during September 1984. After we acquired oral informed consent from parents 756 children aged up to 60 months on 1 October 1984 were enrolled and kept under surveillance until follow up was stopped by death, the subjects leaving the village, or the end of the study on 30 April 1986. Children born during the study to families originally selected were also enrolled.

\section{ACQUISITION OF DATA}

Enrolled children were surveyed each week in their homes. The information gathered at each visit included the number and consistency of stools, vomiting, and fever. Diarrhoea was defined as the passage of four or more liquid stools a day, and a child was considered to have recovered from an episode of diarrhoea when three or fewer stools were passed daily. Two episodes of diarrhoea had to be separated by at least three days without diarrhoea. For breast fed infants below the age of 3 months the definition required the loose motions to be regarded as diarrhoeal stools by the mother. Feeding state was recorded on the last visit of each month and during the diarrhoeal episodes. Exact dates of important transitions like stopping breast feeding and starting or stopping the use of formula milk or solids were also noted.

Four anthropometric surveys were undertaken, the first at the start of the study, the second in April 1985, the third in October 1985, and the last in May 1986. Children were weighed with a beam type scale that read to the nearest $50 \mathrm{~g}$. To evaluate nutritional state weight for age was used, ${ }^{14}$ this being a sensitive indicator of subsequent mortality among children. ${ }^{3}$ Accurate dates of birth were available for $696(92 \%)$ children through a system of registering vital events, which was established in 1980 .

Data collectors were trained specially to collect the data required but were unaware of the hypotheses being tested. A doctor made surprise visits to all households once every two weeks to validate the data collected by fieldworkers and verified $10 \%$ of the weight measurements.

\section{SELECTION OF CASES AND CONTROLS}

For the children with persistent diarrhoea the date of selection was the date of onset of diarrhoea; for the population controls the date of selection was taken as

Dr Bhan. 
the date of onset of diarrhoea for the child to which the control was matched, and for the diarrhoeal controls the date of selection was the date of onset of the acute episode of diarrhoea. The date of selection served as the reference point for ascertaining potential risk factors for the index children and their controls.

Two basic requirements were imposed on all children selected: they had to be aged $<72$ months on the date of selection, and a weight measurement (obtained in the nutritional survey) made between six months and one day before the date of selection had to be available.

Children with persistent diarrhoea were eligible if they had suffered a persistent episode (duration $>14$ days) that started after 1 October 1984 . In children who suffered more than one persistent episode only the first was selected. Of 41 children with persistent episodes aged $<72$ months whose weight had been measured within six months before selection, nine

TABLE I-Comparative features in children with persistent diarrhoeo (index children), population controls, and acute diarrhoeal controls in cohort of children aged <72 months in rural north India, 1985-6. Figures are numbers (percentages) except where stated otherwise

\begin{tabular}{lccc}
\hline & $\begin{array}{c}\text { Index } \\
\text { children } \\
(\mathbf{n}=30)\end{array}$ & $\begin{array}{c}\text { Population } \\
\text { controls } \\
(\mathbf{n}=180)\end{array}$ & $\begin{array}{c}\text { Diarrhoeal } \\
\text { controls } \\
(\mathbf{n}=90)\end{array}$ \\
\hline \multicolumn{4}{c}{ Socioeconomic variable } \\
Age (months): & $24 \cdot 5(15 \cdot 5)$ & $26 \cdot 1(14 \cdot 2)$ & $23 \cdot 5(14 \cdot 6)$ \\
$\quad$ Mean (SD) & $19(6-67)$ & $21(7-67)$ & $25(3-69)$ \\
$\quad$ Median (range) & $15(50)$ & $102(57)$ & $43(48)$ \\
Boys & $18(60)$ & $85(47)$ & $52(58)$ \\
Family income >1100 rupees/year & $9(30)$ & $67(37)$ & $22(24)$ \\
Father had no education & $26(87)$ & $147(82)$ & $72(80)$ \\
Mother had no education & $7 \cdot 9(4 \cdot 7)$ & $7 \cdot 7(3 \cdot 3)$ & $7 \cdot 08(2 \cdot 5)$ \\
Mean (SD) family size & & & \\
Water supply: & $20(67)$ & $100(56)$ & $51(57)$ \\
$\quad$ Handpump & $10(33)$ & $80(44)$ & $39(43)$ \\
Well & Feeding at selection & & \\
Breast fed & $16(53)$ & $94(52)$ & $56(62)$ \\
Breast fed during episode & $17(57)$ & & $61(68)$ \\
Fed formula milk during episode & $23(77)$ & & $78(87)$ \\
\hline
\end{tabular}

TABLE II-Association between weight for age and persistent diarrhoea in rural north Indian children. Comparison of index children with two sets of matched controls

\begin{tabular}{|c|c|c|c|c|c|c|c|}
\hline \multirow[b]{2}{*}{$\begin{array}{l}\text { Weight for } \\
\text { age }(\%)^{\star}\end{array}$} & \multirow{2}{*}{$\begin{array}{c}\text { No }(\%) \text { of } \\
\text { index children } \\
(n=30)\end{array}$} & \multicolumn{3}{|c|}{ Population controls $(n=180)$} & \multicolumn{3}{|c|}{ Diarrhoeal controls $(\mathrm{n}=90)$} \\
\hline & & $\begin{array}{c}\text { No }(\%) \\
\text { of controls }\end{array}$ & Odds ratio $\nmid$ & $\mathrm{p}$ Value & $\begin{array}{c}\text { No }(\%) \\
\text { of controls }\end{array}$ & Odds ratio $\dagger$ & $\mathrm{p}$ Value \\
\hline$\leqslant 70$ & $15(50)$ & $45(25)$ & $3 \cdot 0$ & & $24(27)$ & $2 \cdot 9$ & \\
\hline $71-80$ & $8(27)$ & $72(40)$ & 1.0 & & $34(38)$ & $1 \cdot 1$ & \\
\hline$>80$ & $7(23)$ & $63(35)$ & 1.0 & $0.002 \ddagger$ & $32(36)$ & 1.0 & $0.05 \ddagger$ \\
\hline Iedian & 70 & 77 & & $0.007 \S$ & 76 & & 0.025 \\
\hline
\end{tabular}

$\star$ Weight as percentage of 50 th centile (National Center for Health Statistics)

Odds in nutritional category with reference to $>80 \%$ category $(>80 \%$ taken as 1$)$.

$\neq \chi^{2}$ Test for trend, $1 \mathrm{df}$.

Mann-Whitney U test.

TABLE III-Bivariate matched analysis of association between malnutrition (weight for age $\leqslant 70 \%$ of standard) and persistent diarrhoea

\begin{tabular}{|c|c|c|c|c|c|c|}
\hline \multirow[b]{2}{*}{$\begin{array}{l}\text { No of controls with } \\
\text { weight for age } \leqslant 70 \% \\
\text { in matched sets }\end{array}$} & \multicolumn{3}{|c|}{ Population controls $(n=180)$} & \multicolumn{3}{|c|}{ Diarrhoeal controls $(n=98)$} \\
\hline & $\begin{array}{l}\text { No matched } \\
\text { with index } \\
\text { children with } \\
\text { weight for age } \\
\quad \leqslant 70 \%\end{array}$ & $\begin{array}{c}\text { No matched } \\
\text { with index } \\
\text { children with } \\
\text { weight for age } \\
>70 \%\end{array}$ & Total & $\begin{array}{l}\text { No matched } \\
\text { with index } \\
\text { children with } \\
\text { weight for age } \\
\quad \leqslant 70 \%\end{array}$ & $\begin{array}{l}\text { No matched } \\
\text { with index } \\
\text { children with } \\
\text { weight for age } \\
>70 \%\end{array}$ & Total \\
\hline 0 & 4 & 4 & 8 & 6 & 0 & 6 \\
\hline 1 & 2 & 4 & 6 & 7 & 7 & 14 \\
\hline 2 & 5 & 5 & 10 & 2 & 3 & 5 \\
\hline 3 & 3 & 2 & 5 & 0 & 5 & 5 \\
\hline 4 & 1 & 0 & 1 & & & \\
\hline 5 & 0 & 0 & 0 & & & \\
\hline 6 & 0 & 0 & 0 & & & \\
\hline Total & 15 & 15 & 30 & 15 & 15 & 30 \\
\hline \multicolumn{7}{|l|}{$\begin{array}{l}\text { Matched odds } \\
\text { (95\% confidence } \\
\text { interval) }\end{array}$} \\
\hline
\end{tabular}

$\star$ Weight as percentage of 50 th centile (National Center for Health Statistics). were excluded because they were not suffering from the first persistent episode and two because they had had persistent diarrhoea on 1 October 1984.

All eligible children in the cohort were examined to identify potential population controls for each index child. A potential control for a child had to have been in the study on the date of selection of the index child, to be matched for age (0-11 months, $12-35$ months, $\geqslant 36$ months), and to have been free of persistent diarrhoea until the end of the study. Of the 621 eligible children, $590(90 \cdot 8 \%)$ were considered to be potential controls, the rest being excluded for not being matched for age or for having persistent diarrhoea at the last visit. Out of the potential controls, six were randomly selected for each index child with the statistical package for the social sciences (SPSS).${ }^{15}$ This selection process was followed in ascending order of the date of selection of the children with persistent diarrhoea. Once a child was selected as a control he or she was not reconsidered for selection.

As for the population controls, a list of potential diarrhoeal controls for each index child was generated by computer; these were children who had suffered acute diarrhoea (duration $\leqslant 14$ days) within one month of the date of selection of the index child, had not suffered a persistent episode during the study, and were matched by age to the index child ( $0-11$ months, $12-35$ months, $\geqslant 36$ months). Of the 621 eligible children, $420(67 \cdot 6 \%)$ had had acute diarrhoea in the same month as the index child. Of these, $163(38.8 \%)$ were considered to be potential controls who fulfilled other matching conditions. Of the potential controls, three were selected randomly for each case. Once a child was selected as a control he or she was not reconsidered for selection.

ANALYSIS

Matched odds ratios, the standard measure of association between exposure and disease in a matched case-control study, were calculated in both analyses separately. ${ }^{15}$ Contingency tables (two by two) were evaluated with the $\chi^{2}$ test and Fisher's exact test, when appropriate, to calculate $\mathrm{p}$ values. Two by $\mathrm{n}$ tables were evaluated with the $\chi^{2}$ test for trend. We calculated $95 \%$ confidence intervals for odds ratios by Cornfield's method. ${ }^{16}{ }^{17}$ Summary odds ratios in stratified analysis adjusted for effect of the potential confounders were estimated with $95 \%$ confidence intervals and $p$ values with techniques based on Mantel-Haenszel and Miettinen's tests ${ }^{18}{ }^{19}$ (Epi info ver 3.0 software). The heterogeneity and linear trend of the odds ratio over several variables were calculated with conventional techniques. ${ }^{17}$ To assess the simultaneous confounding effect of several variables on the observed association we fitted the confounding variables with nutritional state as independent variables in a conditional logistic regression model appropriate for matched studies, in which case-control state was the dependent variable.

\section{Results}

Table I compares the index children and the two sets of controls with regard to several factors that might have influenced the relation of malnutrition to persistent diarrhoea. Out of 30 case-control sets, four were aged 0-11 months, 22 were aged 12-35 months, and four were aged $\geqslant 36$ months. Of the factors examined, none showed a significant difference in either analysis, but some differences between index children and controls were noteworthy. Index children tended to have uneducated mothers and belonged to larger families compared with both sets of controls and were less frequently breast fed during the diarrhoeal episode compared with the diarrhoeal controls.

Table II gives the unmatched relation of nutritional 
state to persistent diarrhoea. The median weight for age in the index children $(69.9 \%)$ was lower than that in the population controls $(77 \%, \mathrm{p}<0.007)$ and diarrhoeal controls $(76.2 \%, \mathrm{p}<0.04) ; 23 \%$ of the index children had weight for age $>80 \%$ compared with $35 \%$ of the population controls and $36 \%$ of the diarrhoeal controls.

Table III presents results of the univariate matched analysis of the relation between malnutrition and persistent diarrhoea. Weight for age was divided into $\$ 70 \%$ and $>70 \%$ to identify an undernourished group. Weight for age $\leqslant 70 \%$ has been shown to identify malnourished children with a much higher risk of death over the subsequent six months in north Indian children. ${ }^{7}$ Both matched analyses showed a significant association between antecedent weight for age $\leqslant 70 \%$ and persistent diarrhoea.

To assess the confounding effect of each variable shown in table I on the association between malnutrition and persistent diarrhoea we calculated the maximum likelihood summary odds ratio and significance for association. In no case was either the magnitude or the significance of association between malnutrition and persistent diarrhoea substantially affected.

To evaluate the joint confounding effect of several variables all predictive variables (age ( $<6$ months, 6-11 months, $12-17$ months, $18-23$ months, $24-29$ months, 30-35 months, 36-41 months), and >41 months), sex (male/female), breast feeding (yes/no), family income (above or below 1100 rupees/year), father's education (none/some), mother's education (none/some), family size (seven or fewer), and source of water (well or handpump)) with nutritional state were fitted as independent variables into a conditional logistic regression model that had case-control state as the dependent variable. The multivariate analysis showed a matched odds ratio that related malnutrition to persistent diarrhoea of $3 \cdot 2(95 \%$ confidence interval $1 \cdot 3$ to $8 \cdot 1, \mathrm{p}<0 \cdot 01)$ in the first analysis and $3 \cdot 4(1 \cdot 2$ to $9 \cdot 1, \mathrm{p}<0.02)$ in the second. These were marginally different from the odds of $3 \cdot 3(1 \cdot 5$ to $7 \cdot 3, \mathrm{p}<0.005)$ and $2.5(1.0$ to $5.8, \mathrm{p}<0.05)$, respectively, in the crude matched analysis. No other variable was significant $(\mathrm{p}>0.05)$ in either analysis.

\section{Discussion}

Our study showed that malnutrition, defined as weight for age $\leqslant 70 \%$, was associated with an increased risk of persistent diarrhoea and that it also altered the outcome of acute diarrhoea by increasing the risk of its persisting.

Previously, Tomkins from Nigeria ${ }^{12}$ and Black et al from Bangladesh ${ }^{13}$ reported a longer mean duration of acute diarrhoea in malnourished children. Whereas Tomkins found prolonged diarrhoea in underweight or stunted children, ${ }^{12}$ Black et al found that malnutrition was associated with longer episodes only in diarrhoea due to enterotoxigenic Escherichia coli. ${ }^{13}$ Our findings, together with these earlier reports, suggest that antecedent malnutrition is a risk factor for increasing mean duration of diarrhoea and for persistent diarrhoea.

The increased risk of persistent diarrhoea in malnourished children may be due to several factors. Malnutrition caused by altering protective host factors (hypochlorhydria, altered gut motility, reduced antibody synthesis, and impaired cellular immunity) favours intestinal colonisation by pathogenic microbes..$^{20-26}$ Impaired cellular immune function has also been reported in mild to moderate malnutrition. ${ }^{27}$ Malnourished children show a decreased turnover of epithelial cells after infections, which might cause delayed recovery of the intestinal mucosa. Brunser et al noted a lower mitotic index of mucosal cells in marasmic children, ${ }^{28}$ and such a delay in mucosal recovery might prolong an episode of infectious diarrhoea by itself as well as by promoting tissue invasion by other enteropathogens. Finally, persistent diarrhoea in fairly malnourished children may be due ta persistent malabsorption of lactose. ${ }^{29-31}$

Some potential limitations that could have affected the findings of this study require consideration. Weight and height are the most commonly used anthropometric markers of nutritional state. The use of a child's relative weight for age is often limited by the lack of accurate data on age (not the case in our study), and this variable also lacks the ability to discriminate between acute and chronic malnutrition.

We excluded from analysis children for whom no appropriate measurement of weight was available. To ascertain whether these exclusions had distorted the observed association between malnutrition and persistent diarrhoea we performed intragroup comparisons among the index cases, population controls, and diarrhoeal controls, comparing those with available weights with those without for several features, including income, size of family, education of father and mother, water supply, and diarrhoeal morbidity. There was no significant difference in these variables between those with and without a measurement of weight among index cases and both groups of controls, suggesting that the exclusion had not resulted in bias.

The apparent association of malnutrition with persistent diarrhoea could have been biased if children who were malnourished had an inherently higher risk of persistent diarrhoea because of other risk factors. This possibility is opposed by the fact that the relation of malnutrition and persistent diarrhoea was unaffected by the analytical adjustment for several potential confounders. None the less, unmeasured factors may have distorted the observed relation.

As the measurements of weight were obtained at any time in the six months before the date of selection the differences in the time that elapsed between the measurement and the onset of diarrhoea may have been a source of bias. To ascertain this we categorised the time between measurement of the weight and the date of selection by intervals of 30 days and calculated summary odds ratios. The odds ratio relating malnutrition to persistence of diarrhoea corrected for this elapsed period (in the first analysis crude odds 3.0 , corrected odds $2 \cdot 83,95 \%$ confidence interval $1 \cdot 26$ to $7 \cdot 26, \mathrm{p}<0 \cdot 009$; in the second analysis crude odds $2 \cdot 75$, corrected odds $2.44,1.01$ to $6.66, \mathrm{p}<0.04$ ) did not change appreciably from the crude estimate.

In conclusion, our findings suggest that weight for age $\leqslant 70 \%$ is associated with an increased risk of persistent diarrhoea in the general population. Once diarrhoea begins an underweight child (weight for age $\leqslant 70 \%$ ) has a higher risk of the episode becoming persistent. Hence prevention or prompt treatment of malnutrition will probably reduce the incidence of persistent diarrhoea and prevent the resultant adverse nutritional consequences. In addition, children who are malnourished and develop diarrhoea may require more intensive management to prevent persistence of the diarrhoea.

This study was supported by a grant from the Indian Department of Science and Technology and the Control of Diarrhoeal Disease programme, World Health Organisation, Geneva. We thank D K Kashyap for help with the computer.

\footnotetext{
I Walsh JA, Warren KS. Selective primary health care: an interim strategy for disease control in developing countries. N Engl F Med 1979;301:967-74 2 Scrimshaw NS, Taylor CE, Gordon JE. Interactions of nutrition and infection s. Geneva: World Health Organisation, 1968. (WHO Monograph No 57.) 3 Rowland MGM, Cole TJ, Whitehead RG. A quantitative study into the role of infection in determining nutritional status in Gambian village children. Brf Nutr 1977;37:441-50.

4 Black RE, Brown KH, Becker S. Effects of diarrhea associated with specific
} 
enteropathogens on the growth of children in rural Bangladesh. Pediatrics 1984;73:799-80s.

5 Martorell R, Habicht JP, Yarborough C, Lechtig A, Klein RE, Western KA. Acute morbidity and physical growth in rural Guatemalan children. $A m \mathcal{f}$ Dis Child 1975;129:1296-301.

6 Black RE, Merson MH, Taylor PR, et al. Glucose vs sucrose in oral rehydration solutions for infants and young children with rotavinusassociated diarrhea. Pediatrics 1981;67:79-83.

7 Kielmañn AA, McCord C. Weight-for-age as an index of risk of death in children. Lancet 1978; $1: 1247-50$

8 Chen LC, Chowdhury AKMA, Huffman SA. Anthropometric assessment.of energy-protein malnutrition and subsequent risk of mortality among preschool aged children. Am $\mathcal{F}$ Clin Nutr 1980;33:1836-45.

9 Trowbridge FL, Newton LH. Seasonal changes in malnutrition and diarrheal disease among preschool children in El Salvador. Am $f$ Trop Med Hyg 1979;28:135-41

10 Trowbridge FL, Newton LH, Campbell CC. Nutritional status and the severity of diarrhoea. Lancet $1981 ; \mathrm{i}: 1375$.

11 Gordon JE, Guzman MA, Ascoli W, Scrimshaw NS. Acute diarrheal diseas in less developed countries. 2. Patterns of epidemiological behavior in rural Guatemalan villages. Bull WHO 1964;31:9-20.

12 Tomkins A. Nutritional status and severity of diarrhoea among preschool children in rural Nigeria. Lancet $1981 ; \mathrm{i}: 860-2$.

13 Black RE, Brown $\mathrm{KH}$, Becker S. Malnutrition is a determining factor in diarrheal duration, but not incidence, among young children in a longitudinal study in rural Bangladesh 1-3. Am $\mathcal{F}$ Clin Nutr 1984;39:87-94.

14 Gomez F, Galvan RR, Cravioto J, Frenk S. Malnutrition in infancy and childhood, with special reference to kwashiorkor. In: Levine SZ, ed. childhood, with special reference to kwashiorkor. In: Levine SZ, ed.

15 Nie NH, Hull CH, Jenkins JG, Steinbronner K, Bent DH. Statistical package for the social sciences. New York: McGraw Hill, 1975.

16 Breslow NE, Day NE. Statistical methods in cancer research. Vol 1 . The analysis Breslow NE, Day NE. Statistical methods in cancer research. Vol 1. The analysis
of case-control studies. Lyons: International Association for Research on Cancer, 1980:142-3. (Scientific publication No 32.)

17 Rothman KJ, Boice JD. Epidemiologic analysis with a programmable calculator. Boston: Epidemiology Resources, 1982:5-7.
18 Miettinen OS. Estimability and estimation in case-referent studies. Am $\mathcal{J}$ Epidemiol 1976;103:226-35.

19 Schlesselman J. Case control studies. Design, conduct, analysis. New York: Oxford University Press, 1982:227-90.

20 Munson D, Franco D, Arbeter A, Velez H, Vitale JJ. Serum levels of immunoglobulins, cell-mediated immunity and phagocytosis in proteincalories malnutrition. Am f Clin Nutr 1974;27:625-8.

21 Schlesinger D, Stekel A. Impaired cellular immunity in marasmic infants. Am f Clin Nutr 1974;27:615-20.

22 Purtilo DT, Riggs RS, Evans R, Neafie RC. Humoral immunity of parasitized, malnourished children. Am $\mathcal{Y}$ Trop Med Hyg 1976;25:229-32

23 Koster F, Gaffar A, Jackson TM. Recovery of cellular immune competence during treatment of protein-calorie malnutrition. Am $\mathcal{F}$ Clin Nutr 1981;34 $887-91$.

24 Chandra RK. Reduced secretory antibody response to live attenuated measles and poliovirus vaccine in malnourished children. Br Med $\mathcal{F} 1975$;ii:583-5.

25 Sirisinha S, Suskind R, Edelman R, Asvapaka C, Olson RE. Secretory an serum IgA in children with protein-calorie malnutrition. Pediatrics 1975; 55:166-70.

26 Green F, Heyworth B. Immunoglobulin-containing cells in jejunal mucosa of children with protein energy malnutrition and gastroenteritis. Arch Dis Child 1980;55:380-3.

27 Kielmann AA, Uberoi IS, Chandra RK, et al. The effect of nutritional status on immune capacity and immune responses in preschool children in a rural community in India. Bull WHO 1976;54:477-83.

28 Brunser O, Reid A, Monckeberg F, Maccioni A, Contreras I. Jejunal mucosa in infant malnutrition. Am $\mathcal{F}$ Clin Nutr 1968;21:976-83.

29 Hisschhorn N, Molla A, Molla AM. Reversible jejunal disaccharidase deficiency in cholera and other acute diarrheal diseases. Johns Hopkins Medical foumal 1969;125:291-300.

30 Coello-Ramirez P, Lifshitz F, Zuniga V. Enteric microflora and carbohydrate intolerance in infants with diarrhea. Pediatrics 1972;49:233-42.

31 Gribbin M, Walker-Smith J, Wood C. Delayed recovery following acute gastroenteritis. Acta Paediatrica Belgica 1976;29:167-76.

(Accepted 17 February 1989)
National Public Health Institute, Mannerheimintie 166, SF-00300 Helsinki, Finland

Bernard Marti, MD, research fellow

Jaakko Tuomilehto, MD, professor

Heikki J Korhonen, MD, research fellow

Leena Kartovaara, MPOLSC, systems analyst

Erkki Vartiainen, MD, assistant professor

Pirjo Pietinen, DSC, assistant professor

Pekka Puska, MD, professor

Correspondence to: $\mathrm{Dr}$ Tuomilehto.

BrMed f 1989;298:1287-90

\title{
Smoking and leanness: evidence for change in Finland
}

\author{
Bernard Marti, Jaakko Tuomilehto, Heikki J Korhonen, Leena Kartovaara, Erkki Vartiainen, \\ Pirjo Pietinen, Pekka Puska
}

\begin{abstract}
Many studies have shown smokers to weigh less than non-smokers, which is plausible given the metabolic effects of cigarette smoke. The interrelation between smoking and relative body weight and its change over time were analysed by using data from Finnish population based surveys from 1982 and 1987. Among both men and women the inverse association between smoking and body mass index was clearly weakened between 1982 and 1987 . In 1987 among men aged 25-44 smoking was positively related to body mass index. Moreover, the relation between smoking and waist to hip girth ratio was positive in both sexes at all ages. Years of smoking was nevertheless confirmed as a significant inverse predictor of relative weight. A cluster of unfavourable health habits, including high consumption of alcohol and saturated fats, especially emerged among younger smokers. This may have been due to different selection of smokers in Finland, where smoking increasingly seems to be a form of deviant or risk taking behaviour.
\end{abstract}

It is concluded that at a population level the metabolic effects of smoking seem to be increasingly overridden by several other unfavourable health behaviours of smokers.

\section{Introduction}

Numerous epidemiological studies have compared the body weights of smokers and non-smokers, and nearly all have found that smokers as a group weigh less than people who have never smoked. ${ }^{1-11}$ Among men the inverse association between smoking and body weight is strongest in older smokers and weakest in younger smokers, which may be due to the duration of smoking. ${ }^{347}$ For example, metabolic studies have shown that smokers have an increased resting energy expenditure. ${ }^{12}$ Behavioural, environmental, and cognitive factors, however, are also active determinants of diet, exercise, and body weight. ${ }^{4}$ Indeed, smoking has shown a $U$ shaped relation with relative weight in several studies, smokers of 5-20 cigarettes a day being the leanest. ${ }^{2357813}$

Though paradoxical given the metabolic effects of smoking, possibly heavier smokers may weigh more because they have other unhealthy habits such as heavy drinking and little exercise. ${ }^{14}$ 15

This paper examines the association between smoking and body mass index among the Finnish population in 1982 and 1987. The study used population based data collected as part of the World Health Organisation's multinational project of monitoring trends and determinants in cardiovascular diseases (MONICA). ${ }^{16}$

\section{Subjects and methods}

In 1982 and 1987 cross sectional surveys of risk factors were carried out in four areas in Finland. ${ }^{16}$ Independent random samples were drawn from these four populations covering the age range 25-64 years. Response rates in the surveys were $80-94 \% .^{16} 17$ This analysis is based on data from 4508 men and 4648 women in 1982 and 2913 men and 3212 women in 1987. The surveys included a self administered questionnaire checked by an interviewer and physical measurements. Weight, height, and girth of waist and hips were measured in light clothing by trained personnel. The body mass index (weight $(\mathrm{kg}$ ) divided by height (m) squared) was used as a measure of relative body weight.

Information on smoking was obtained by seven standardised questions in the questionnaire. Those subjects who reported that they had smoked regularly for at least a year and at least once a day on average 